\title{
Decision making and experiences of young adults undergoing presymptomatic genetic testing for familial cancer: a longitudinal grounded theory study
}

\author{
Lea Godino $^{1,2} \cdot$ Leigh Jackson $^{2} \cdot$ Daniela Turchetti $^{1} \cdot$ Catherine Hennessy $^{3} \cdot$ Heather Skirton $^{2}$
}

Received: 2 August 2017 / Accepted: 26 September 2017 / Published online: 21 November 2017

(C) European Society of Human Genetics 2018

\begin{abstract}
Enabling informed choice is an essential component of care when offering young adults presymptomatic testing for a genetic condition. A systematic review on this topic revealed that many young adults grew up with little information regarding their genetic risk and that parents had applied pressure to them during the testing decision-making process. However, none of the studies retrieved were conducted in South European countries. To address this gap, we undertook a qualitative study based on grounded theory to explore the psychosocial implications of presymptomatic testing for hereditary cancer in Italian young adults aged 18-30 years. Interviews were conducted on three occasions: 1 month before counselling, and 2 weeks and 6 months after results. Data were coded and grouped under themes. A total of 42 interviews were conducted. Four themes emerged: knowledge, genetic counselling process, decision making and dealing with test results. Although participants grew up with little or no information about their genetic risk, none expressed regret at having the test at a young age. Pre-test counselling was appreciated as a source of information, rather than support for decision making. Decisions were often made autonomously and sometimes conflicted with parents' wishes. Participants reported no changes in health behaviours after testing. This evidence highlights the need for a comprehensive, longitudinal counselling process with appropriate timing and setting, which supports 'parent-to-offspring' risk communication first and decision making by young adults about presymptomatic testing and risk management afterwards. In conclusion, it is clear that counselling approaches for presymptomatic testing may require modification both for young adults and their parents.
\end{abstract}

\section{Introduction}

Presymptomatic genetic testing (PST) involves testing to determine if a person has inherited a gene variant that causes a condition known to be present in the family, before they exhibit any signs or symptoms of the condition. Those

Electronic supplementary material The online version of this article (https://doi.org/10.1038/s41431-017-0030-1) contains supplementary material, which is available to authorized users.

$\triangle$ Lea Godino

lea.godino@studio.unibo.it

1 Center for Studies on Hereditary Cancer, Department of Medical and Surgical Sciences, University of Bologna, and Unit of Medical Genetics, S.Orsola-Malpighi Hospital, Bologna 40138, Italy

2 School of Nursing and Midwifery, Faculty of Health and Human Sciences, Plymouth University, Plymouth PL4 8AA, UK

3 Faculty of Health and Social Sciences, School of Health and Social Care, Bournemouth University, Bournemouth BH12 5BB, UK at risk of heritable genetic disorders, including hereditary cancer syndromes [1] may be able to access PST to determine their genetic status and potentially alter lifestyle choices or seek early treatment for symptoms $[2,3]$. Presymptomatic testing of minors (under the age of 18 years) in this situation is not usually recommended [4, 5], although the age at which young people should be able to undergo PST for adult-onset disorders is a matter of debate $[5,6]$. Key challenges that typically have to be faced during the transition from adolescence to adulthood include marriage, completing education, beginning full-time employment and becoming a parent: the impact of testing may affect, and be affected by, each of these events.

A variety of psychosocial responses have been observed in those who have chosen to be tested [7]. The appropriate age to offer PST is a matter of debate: it is suggested that undergoing PST too early in life may increase the risk of unfavourable impact [8-10]. For these reasons, individuals aged less than 18 years are not usually offered PST for adult-onset disorders, the exceptions being if testing is 
considered to be in a child's best interests [4]. Conversely, according to guidelines used in the United Kingdom (UK), people aged 16 or 17 years are presumed to be capable of consenting to their own medical treatment, and, in specific cases, children under 16 years who are adjudged to fully understand what is involved in a proposed intervention will also have the capacity to consent to that intervention [11]: in other European countries adolescents have access to medical treatment by law. In addition, it has been argued that young persons who are considered as adults on the agebased criterion of 18 years are not all necessarily truly autonomous [9]. There is no specific age when a person is able to give autonomous consent, but it is important to consider psychological maturity [9] that is cumulative with age, life experience and cognitive development [12], while maturity of judgement depends upon responsibility, temperance, and perspective [12].

Prior to testing, young adults (YA) need to be aware of the potential risk to them of hereditary cancer, and this is usually disclosed by their parents [13-15]. Prevalence and experiences of parental communication of BRCA results to children under the age of 25 were described by Bradbury et al. [16]: $55 \%$ of parents $(n=23 / 25)$ reported sharing family history and/or genetic risk with at least one child. Their results indicate that the $42.9 \% \quad(n=18)$ of children in these families were learning of their potential genetic risk of cancer before the age of 18 and 57\% ( $n=24)$ between 18 and 25 years of age. It came to light in that study that children of those with a BRCA variant learnt of their parent's genetic test results many years before preventive interventions were indicated. In fact, in a study of 273 women tested for hereditary breast and ovarian cancer variant, Patenaude et al. [13] noted that, although most children were told by their mother, the child's age influenced the communication with offspring: they showed there was no significant difference between numbers of minors (14-17 years, 85\%) and YA (18-30 years, 92\%) informed of the risk by their parents. Borry et al. [4], in their paper on PST in asymptomatic minors, concluded that minors, considering their age and degree of maturity, are able to participate in decision making and their opinions regarding PST should be taken into consideration.

A systematic review [17] on this topic indicated that many YA grew up with little or no information concerning their genetic risk and that parents had exerted pressure during the testing decision-making process. The experience of genetic counselling (GC) was either reported as an opportunity for discussing problems or associated with feelings of disempowerment. Moreover, emotional outcomes of disclosure did not correlate with test results. However, none of the studies retrieved were conducted in Italy or other South European countries. To address this gap, we undertook a qualitative study based on grounded theory to explore the psychosocial implications of PST for hereditary cancer in Italian YA aged 18-30 years.

\section{Materials and methods}

This was a qualitative study in which we employed a grounded theory approach. This approach was specifically chosen to explore the experiences of YA from their own perspective, in this case the subjective meanings associated with being at risk for hereditary cancer and their involvement with a health care technology and clinical process for risk identification and reduction. This study received ethics approval both from Plymouth University Faculty Research Ethics Committee (14/15-324), and St. Orsola-Malpighi Hospital Ethical Board (132/2014/O/Oss).

In order to follow YA through the process of GC, from referral to follow-up, a longitudinal study design was chosen. This enabled the authors to obtain data before these were altered by the YA's contact with the genetic service, as well as providing the opportunity to assess how perceived needs, expectations, and knowledge changed over the period of contact. Each participant was interviewed on three separate occasions: one month before GC, and 2 weeks and 6 months, respectively, after GC.

\section{Recruitment and participants}

All participants were recruited at the Genetics Unit of St. Orsola-Malpighi Hospital (Bologna, Italy). Every new young consultand making an appointment for the cancer genetics clinic was contacted before the consultation via telephone and invited to take part in the study. Inclusion and exclusion criteria are presented in Fig. 1. The process of recruitment, interviews and data analysis was ongoing until data saturation [18] was reached and no new categories were emerging.

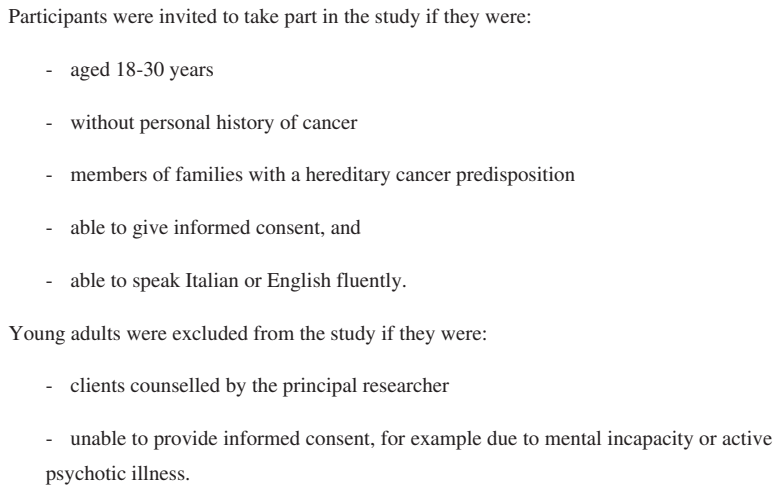

Fig. 1 Inclusion and exclusion criteria 


\section{Data collection}

Face-to-face interviews were organised with participants who responded to an invitation to be involved in the study. All interviews were performed by LG (a genetic nurse with training in counselling skills and 5 years of experience in GC), to ensure that the participants were subject to a constant interviewer effect. Each interview began with questions regarding demographic information. Later sections were designed to understand the attitudes of YA, to evaluate their cancer perception and psychological status and to explore the extent to which the parents' influence had been important. In addition, questions were refined and amended over the course of the interviews to take into account possible theories emerging from the data. The interviews were performed with the participant only: any accompanying person was waiting outside. The interviews were written in Italian (English version in Supplementary File). Data were collected using a digital recording device and interviews were transcribed verbatim, with names and other identifying material altered to ensure confidentiality.

\section{Data analysis}

Data were analysed using the grounded theory method [18]: each interview was analysed as soon after transcription as possible. The software package NVivo, version 10 (QRS international, Pty, Ltd) was used to help organise the data. The primary author listened to the digital recordings and transcribed the interviews. Statements were subsequently coded (open coding) from the transcribed material. All the interviews were translated into English by LG and an expert translator and checked by DT to ensure accuracy of translation and sense, and so improve rigour. The first 21 interviews were sent to other co-authors (HS and LJ) to code independently to further ensure rigour and as there was substantial agreement, the remaining interviews were coded by LG. The codes and emerging categories derived by the co-authors were then compared to ensure trustworthiness of the findings. Any disagreements were discussed until consensus was reached. Finally, the data were further synthesised by grouping categories into major themes to establish the relationships between data from all participants (axial coding).

\section{Results}

Seventeen invitations were sent to potential participants: 14 (82.4\%) accepted and were interviewed (Fig. 2). In total, 42 interviews were conducted with 14 participants. The participant characteristics are presented in Tables 1 and 2 . Respondent ages ranged from 18 to 30, with a mean age of
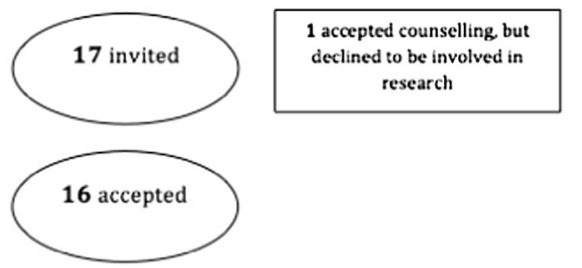

$\underline{\text { 1"I INTERVIEW }}$

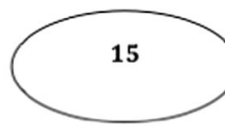

1 declined counselling and withdrew from research

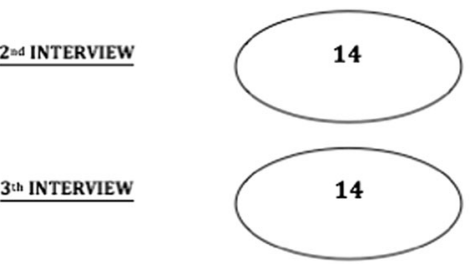

1 declined second interview and withdrew from research

Fig. 2 The recruitment process

25.3 years. The characteristics of the participants' parents (based on information provided by the YA) are presented in a Supplementary Table.

Four major themes were identified. The pseudonym and interview number with that participant (Int 1, 2 or 3) are included after each direct participant quote.

\section{Knowledge}

Many YA reported having grown up without awareness of or with misinformation about the hereditary cancer running in their family. Following their first GC appointment, some YA affirmed that as a result of the GC session their knowledge had improved:

'Although the pathogenic gene contaminated the female organs, I thought my mom could have transmitted the pathogenic gene to me and it could have contaminated every single organ. At the beginning I was very confused.' (Mario, age 26, Int 2)

Despite misinformation or lack of awareness, YA reported that the family history had an important role in terms of their awareness and that it affected their feelings. 'Having a family member diagnosed with cancer definitely makes you more aware of cancer.' (Donato, age 30, Int 3). Another important issue for participants was realising the need for surveillance. Some had not yet started any additional clinical surveillance that would have been relevant for the familial condition. 'I want to prevent [...] I'll do anything to stay healthy [...] I want to live!' (Barbara, age 29 years, Int 3). After GC, YA became aware of the options for clinical screening, and the possibility of having more frequent screening without undergoing PST: 'It was not required to proceed to the standard routine of undergoing 
Table 1 Description of participant characteristics

Gender $N(\%)$

$\begin{array}{ll}\text { Male } & 6(42.9 \%) \\ \text { Female } & 8(57.1 \%)\end{array}$

Age at interview (years)

$$
\text { Mean } \pm \text { SD } \quad 25.3 \pm 3.6
$$

Country of birth $N(\%)$

$\begin{array}{ll}\text { Italy } & 13(92.9 \%) \\ \text { Poland } & 1(7.1 \%)\end{array}$

Mother's language $N(\%)$

$\begin{array}{ll}\text { Italian } & 13(92.9 \%) \\ \text { Polish } & 1(7.1 \%)\end{array}$

Condition tested for $N(\%)$

$\begin{array}{ll}\text { BRCA1 } & 8(57.2 \%) \\ \text { BRCA2 } & 5(35.7 \%) \\ \text { MLH1 } & 1(7.1 \%)\end{array}$

Age at test (years)

$\begin{array}{ll}\text { Mean } \pm \text { SD } & 25.3 \pm 3.6 \\ \text { Range } & 18-30\end{array}$

Result $N(\%)$

Positive (for mutation)

$4(28.6 \%)$

Negative (for mutation)

$10(71.4 \%)$

Education $N(\%)$

Middle school qualification $1(7.1 \%)$

High school diploma

$7(50.0 \%)$

University degree

$5(35.8 \%)$

Post-graduate degree

$1(7.1 \%)$

Daily work $N(\%)$

$\begin{array}{ll}\text { Student } & 5(35.8 \%) \\ \text { Worker } & 3(21.4 \%) \\ \text { Employee } & 3(21.4 \%) \\ \text { Business owner } & 1(7.1 \%) \\ \text { Unemployed } & 2(14.3 \%)\end{array}$

Marital status $N(\%)$

$\begin{array}{ll}\text { Married } & 1(7.1 \%) \\ \text { Single } & 12(85.8 \%) \\ \text { Living together } & 1(7.1 \%)\end{array}$

Having children $N(\%)$

$\begin{array}{ll}\text { No } & 12(85.7 \%) \\ \text { Yes } & 2(14.3 \%)\end{array}$

the exam, waiting for the results and then later entering the screening; but you could choose to take up screening' (Caterina, age 29 years, Int 2). Nevertheless, one young woman thought that cancer could occur even if the variant was not found and therefore she should have screening because of the family history: 'My family history is that, despite the fact of having the syndrome or not.' (Morena, age 25 years, Int 1). Before GC, PST was described as 'just a blood test' by participants. Waiting for the PST result was another point emphasised by YA. Some reported that was the only thing they wanted to ask the genetic counsellor, for example, one young woman said: 'At the end, I had only one question left and it was about the timing ....... I had no doubts ... but only lack of knowledge' (Morena, age 25 years, Int 2). Also after the GC, the PST was often perceived as 'a need to wait for the result'. One young woman, who experienced a pregnancy, had compared 'the need to wait for the result' with her experience of finding out her baby's gender. Although at first YA did not really know what PST was, after GC they declared that they better understood what they were doing or better understood the importance of undergoing PST. 'I truly understood (the meaning of it all) only after dealing with counselling and questions they asked me' (Barbara, age 29 years, Int 3). At the same time, YA regarded the PST as a medical test like any other. 'An exam like any other. [...] It was an ordinary blood sample.' (Luca, age 24 years, Int 2). Once aware of the family genetic disorder, those who did not understand what it really meant sought information online, while others did not want to use the Internet as a source of research. Nevertheless, YA preferred not to speak about their situation with friends. 'Then I sincerely don't want to analyse my private life too much with my friends.' (Mario, age 26 years, Int 1). Almost all YA were informed of their family genetic status by their mother. In cases where the mother was deceased, the person who had been genetically tested in the family often informed the young adult.

\section{Genetic counselling process}

The experience of the GC process was explored and YA explained their motivations to have it, their expectations and experience of it. Undergoing GC was motivated by curiosity, a need for information, and to obtain certainty. Others focused their attention on undergoing $\mathrm{GC}$ to help prevent cancer. The decision to undergo GC was not always specifically discussed with parents, but YA knew that their relatives had consulted medical professionals and wished to follow a similar pathway. Nevertheless, four participants underwent GC purely for themselves, for example Mario decided to go through GC: 'For a more serene future.' (Mario, age 26 years, Int 1). One of the two YA with children underwent GC because of anxiety about her daughter, while some participants underwent GC to understand the risk to their future children.

The majority of YA interviewed had no expectations about GC, mostly because they lacked knowledge about it. However, they still expected a blood test, as something that genetic counsellors suggested, something they had to do, and something that would be uncomfortable. 'Counselling was the prelude of the genetic test [...] I didn't think I could have said 'no' at the end as well as any other person. [...] I thought it was a required step' (Morena, age 25 years, Int 2). 


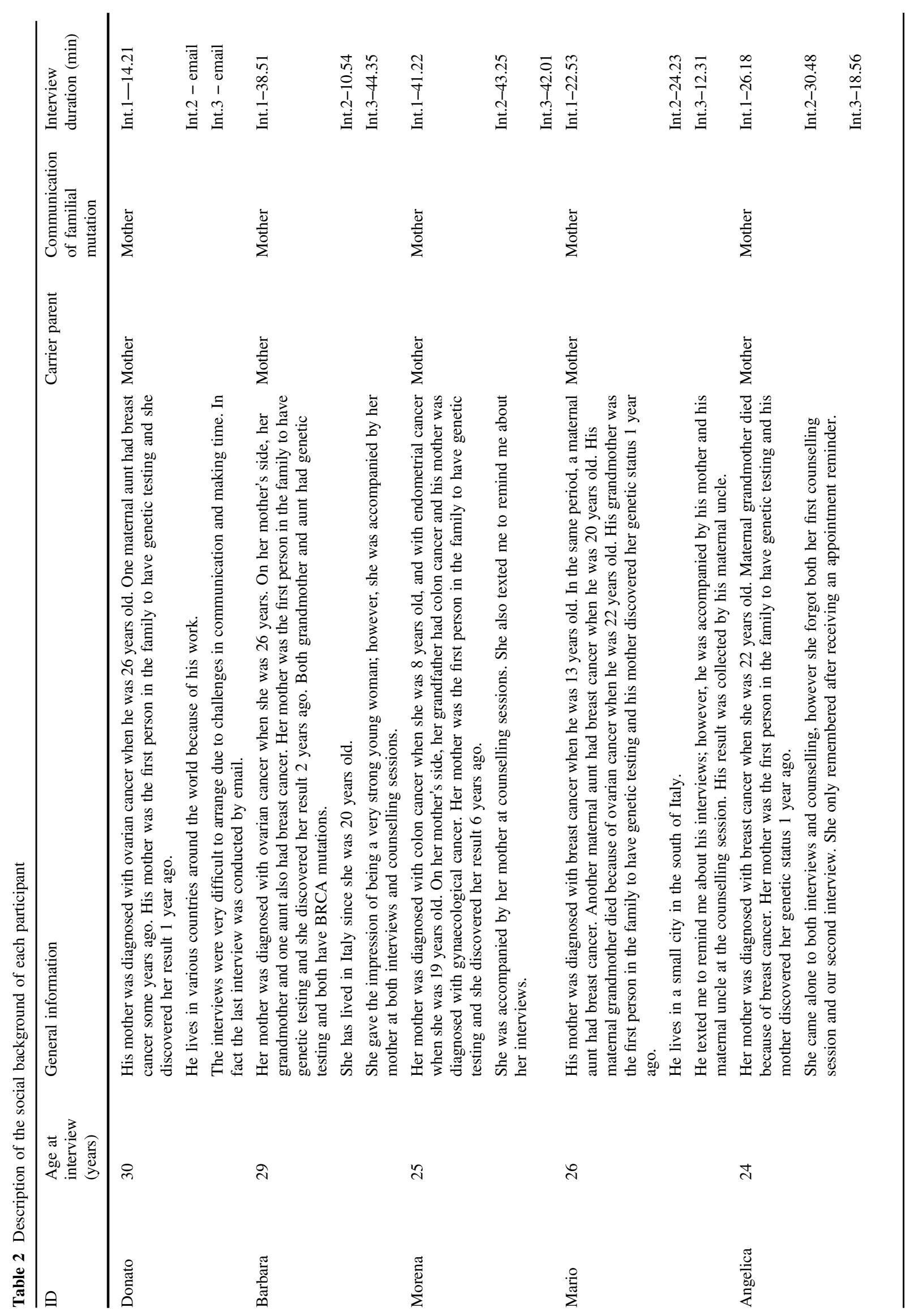




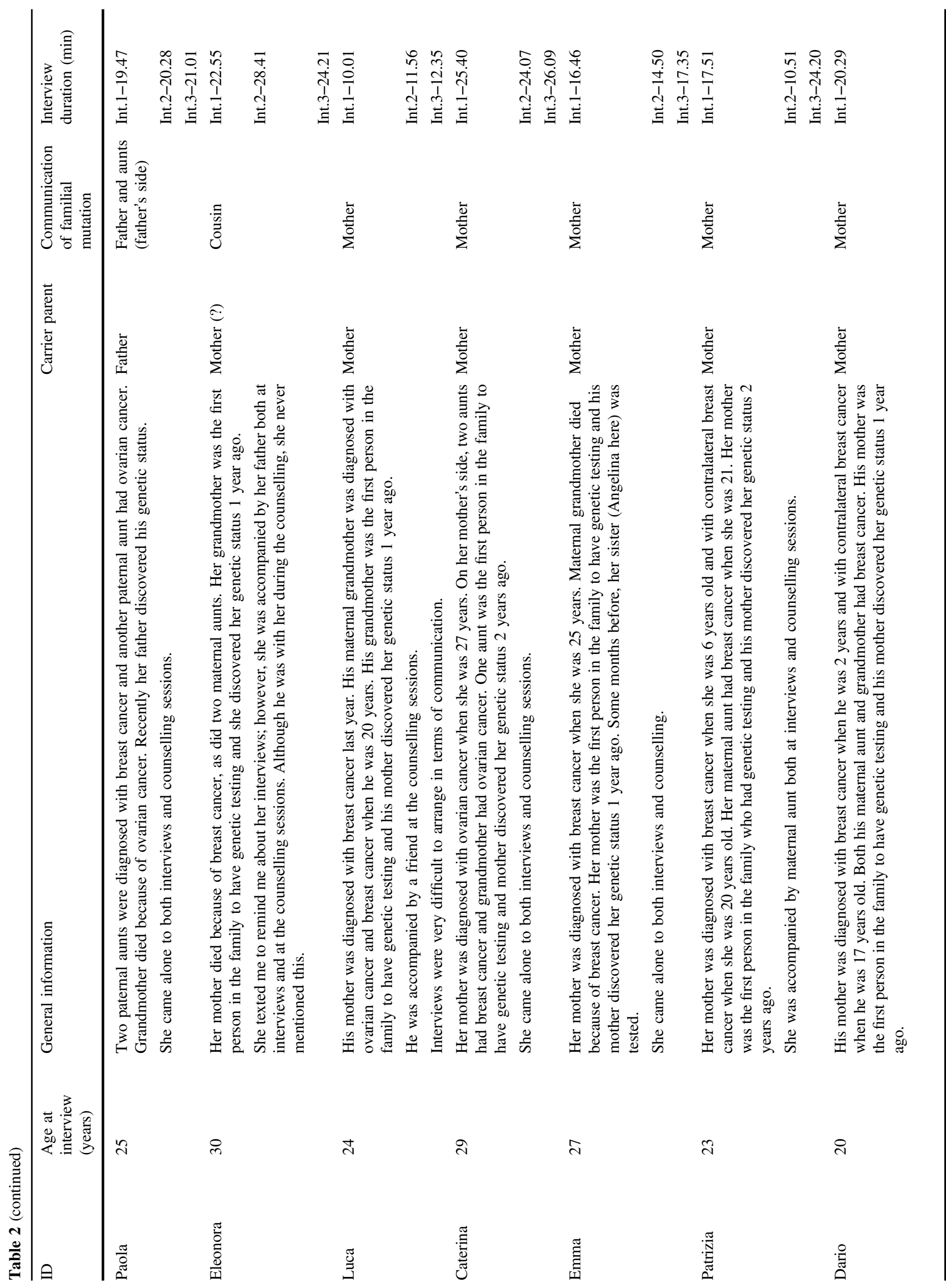


Some YA perceived GC/PST as a 'need to wait for the result', and they were therefore surprised to have the blood sample taken at the first consultation. 'I honestly didn't expect to be tested during the first counselling.' (Barbara, age 29 years, Int 2). Young adults interviewed reported GC had helped them, through the process of discussion with the counsellor. Some positive feelings were expressed about genetic counsellors, such as the perception of being understood and that the counsellor was the person who explained the meaning of testing. Many YA reported that they had not expected to have a choice. They had assumed that, in agreeing to undergo the GC process, they would have a PST and they were surprised when they realised they make a testing decision. 'At the end, they asked me if I wanted to do this thing. I thought counselling ended with the genetic test, instead it didn't! It was the idea I had for months!' (Eleonora, age 30 years, Int 2). All the YA were offered, and underwent, PST at the first GC session except one, who was offered a second pre-test session. She declared she felt more aware of the implications of the test when she underwent it during the second session: 'With hindsight I think the first time I'd have done it unconsciously. [...] today, I'm more conscious about what I'm doing.' (Paola, age 25 years, Int 2). Even if they had already made a clear choice to undergo the PST before the consultation, some expressed a desire to have the genetic counsellor give an opinion to guide them.

\section{Decision making for testing or not}

Although theoretically, making an autonomous choice to undergo PST is a fundamental requirement of the process of GC, some young family members were subject to pressure from their parents to be tested. As a consequence of parental pressure, some YA reported that they underwent PST for the sake of a parent/relative. 'Honestly, because my mother told me and she did it first ... I'm doing it as a favor to her.' (Luca, age 24 years, Int 1). However, differences emerged in the extent of parental involvement in the decision-making process. In some cases, the decision to have a PST was made autonomously but was congruent with the relatives' point of view. 'I called to have an appointment under pressure from my mother ... I'd have done it sooner or later. ....although I would have chosen to wait a bit more.' (Angelica, age 24 years, Int 1). On the other hand, the decision was sometimes at odds with the parent's opinion. 'She (mother) has always been very uncertain whether to get me to do the project. She said: 'You have to think more deeply about it, the result doesn't change'.' (Morena, age 25 years, Int 1). The participants' decision-making process occurred before the first GC session: no participant reported having GC to help facilitate their decision about testing. However, it was not clear whose idea it was to undergo 
PST. Some of them tried to align the decision to have counselling with their perception of the appropriate time to start clinical surveillance. The majority attended the GC session alone, however, even if the participant attended alone, the counselling session was often arranged by the participant's mother, especially for young men. No differences emerged between those whose mothers had booked and those who booked themselves. Nevertheless, a young woman who had decided to bring her mother with her reported that 'Having her there made me experience the counselling as way more touching' (Morena, age 25 years, Int 2).

The majority of YA decided not to share the decision to undergo PST with their friends. Others decided to share it only with close friends because they felt that other people would not understand the complexities of the situation. As Barbara (age 29 years, Int 1) described: 'None of my friends knows (what I'm doing) because I think these are very personal things and, knowing my friends, I'm afraid that some of them might think bad (of me) and then I would feel bad'. Looking back on their experience of PST, three participants expressed a desire for something different from what they had experienced. While Barbara suggested a YA support group to discuss experiences, share ideas, and provide emotional support, others proposed having more professional psychological support.

\section{Dealing with the result}

Some participants perceived PST as a source of tension, mostly before they underwent GC. As Dario (age 20, Int 3) described:'At the beginning, it is normal to feel a little bit scared or worried because it is something unknown ... but when everything is explained one calms down'. Some YA expected that the PST result would be negative. Others, who believed before testing that they would be variant-positive, felt relieved when the test had a different outcome. As Barbara (age 29 years, Int 1) described: 'If I didn't have the gene ... breathe'. However, the PST result was perceived by YA as useful in helping them to plan their lives. Conversely, others did not think that they would change their behaviour based on the possible result. However, when they considered how they might react, the majority affirmed that they did not know.

Once aware of their test result, none of those interviewed reported a catastrophic emotional response: emotions of relief, happiness and fear were generally reported. Accordingly, participants with negative PST results described themselves and their parents as happy to have this knowledge. Regardless of the result, some YA felt they had matured as a result of their testing experience. Moreover, once they had received the result, they recommended that their relatives (e.g., siblings) undergo PST as well. Only
Morena specifically recommended GC to her relatives. Changes in behaviour were not generally reported in either variant-positive or variant-negative YA, however, a young woman who was variant-positive started to pay more attention to her body and possible symptoms.

Young women who were variant-positive, started their surveillance and one of them described herself thaving butterflies' (Barbara, age 29 years, Int 3) after her first screening, nervous about her first ultrasound outcome. Fortunately, it was normal and she felt relieved, but she underlined that the relief would last 'until the next follow-up visit'.

\section{Discussion}

The aim of this study was to investigate the experience of PST in Italian YA aged 18-30 years. The choice of this range of age was made on the basis of the specific Italian context. In Italy, the age at which YA leave the parental home is very high when compared to other countries [19, 20]. It is clear that the activities of young adulthood, e.g., forming partnerships and becoming parents, occur later than in other cultures [20] and this could affect their PST decision making.

The results show that participants grew up with little or no information about their genetic risk and they usually became aware of their risk less than one year before testing. This is in contrast with findings emerging from the papers reviewed in the systematic review [17] where YA were informed several years before testing or clinical actions could be undertaken [21-23]. Considering the Italian context, this may be because of the delay of YA's development into mature adulthood. At the time of the final interview, young adults were consciously, as well as unconsciously, developing strategies to cope with the experience they were facing. There was a dynamic relationship between the decision-making process and their autonomous choice: YA arrived at the decision-making process because of previous knowledge, disclosed by one or both parents. Consistent with this finding, a meta-synthesis of the family communication between children and their parents about inherited genetic conditions conducted by Metcalfe et al. [24] showed that parents were primarily responsible for discussing genetic information with their children. Although there was a desire by parents to tell their children about their potential genetic risk before others told them [24], parents also stressed delaying the disclosure or choosing the right time to talk [25]. No differences emerged between participants who underwent PST when they aged $<24$ years and those who were older, whereas Hamilton [26] reported that older YA were more likely than younger ones to decide autonomously to have PST. Young adults are normally at a stage 
of life in which they are acquiring knowledge about themselves and the world around them [27, 28]. They may or may not be sufficiently mature, or have a realistic set of expectations about what genetic information will allow them to do, or even the health insurance to support risk management decision making $[12,29]$. They may or may not fully understand the science behind PST related cancer risk, gene penetrance, or prevention.

In this study, at the start of the GC process participants had often not understood that their choices had serious implications. Instead, as Lindenmeyer et al. [30] underlined, participants did not choose to undergo PST separate from the collective concerns and desires of their families. Parents may exert pressure on YA children to complete PST [31], however no participants reported the same behaviour as their parents in terms of risk management decisions (e.g. surgery rather than screening).

Concerning the impact of test results, overall, our findings do not support a substantial risk of adverse emotional outcome in variant carriers, which is in agreement with previous findings [32]. In contrast, being variant-positive for Huntington disease may influence a YA's education, career, relationships and family planning [33]. This may be because there is no preventive treatment available at present for that condition, or that the condition is perceived to have much greater impact on functioning throughout life.

Overall, although our results may not be generalisable because of a lack of data from South European countries, differences with other countries emerged. Further study in the Mediterranean area may be needed to clarify if these differences are peculiar to the Italian population or may be generalisable to other countries of this area.

\section{Strengths and limitations}

An identifiable strength of this study was the method chosen, which provided an effective framework for key themes to emerge from the data. Moreover, because of the longitudinal design we have been able to ascertain the views of young adults considering testing both prospectively and retrospectively. A limitation of this study is that we only identified YA who decided to undergo PST, as we were unable to recruit YA who decided not to be tested. Additionally, we were unable to affirm that our results are unique for the age group studied, the comparison with older age groups was not possible as it falls outside the aim of the present study.

\section{Conclusion}

The findings of this study indicate a need for further guidance on PST in these populations: it is important for health professionals to understand how much the YA involved are really aware of the implications before and after they have been tested. It is therefore important to publicise the supportive and educational role of genetic services. Moreover, appropriate communication of genetic risk information by parents to their children is highly desirable, since it has been shown to have long-term consequences [24]. To achieve this, health professionals could have a role in both supporting parents and YA, as their involvement in the parents' decision to communicate genetic risk to young family members was found to be limited [16, 17, 34, 35]. Although this may be partly due to the parents' wish to undertake this task alone, it is reported that some parents desired health professionals to be available in a supporting role, but found this was limited $[24,36]$. This evidence highlights the need for a comprehensive, longitudinal counselling process with appropriate timing and setting, which supports 'parent-tooffspring' risk communication first and YA's decision making about PST and risk management afterwards. In conclusion, it is clear that GC approaches to this population may require modification both for YA and their parents. Further analysis is required to determine how YA and their parents interpret PST, how they experience GC, and the influence that parents have on YA's decisions after the disclosure of the positive test result to inform GC practice in this client group.

Acknowledgements We would like to express our gratitude to the YA who participated in this study. We also acknowledge the Medical Genetics Unit staff of Bologna for identifying and suggesting potential participants and Dr. Annalisa Spinelli for helping us to translate the interviews into English. L.G. was supported by the Grant from Regione Emilia-Romagna 'Diagnostics advances in hereditary breast cancer (DIANE)' (PRUa1GR-2012-001).

\section{Compliance with ethical standards}

Conflict of Interest The authors declare that they have no conflict of interest.

\section{References}

1 Evans JP, Skrzynia C, Burke W. The complexities of predictive genetic testing. BMJ 2001;322:1052-6.

2 Beery TA, Williams JK. Risk reduction and health promotion behaviors following genetic testing for adult-onset disorders. Genet Test 2007;11:111-123.

3 Quaid KA, Sims SL, Swenson MM, Harrison JM, Moskowitz C, Stepanov N, et al. Living at risk: concealing risk and preserving hope in Huntington disease. J Genet Couns 2008;17:117-28.

4 Borry P, Evers-Kiebooms G, Cornel MC, Clarke A, Dierickx K. Genetic testing in asymptomatic minors: background considerations towards ESHG Recommendations. Eur J Hum Genet 2009;17:711-719.

5 MacLeod R, Tibben A, Frontali M, Evers-Kiebooms G, Jones A, Martinez-Descales A, et al. Recommendations for the predictive genetic test in Huntington's disease. Clin Genet 2013;83:221-231. 
6 Borry P, Evers-Kiebooms G, Cornel MC, Clarke A, Dierickx K. Genetic testing in asymptomatic minorsBackground considerations towards ESHG Recommendations. Eur J Hum Genet 2009;17:711-719.

7 Baig SS, Strong M, Rosser E, Taverner NV, Glew R, Miedzybrodzka Z, et al. 22 Years of predictive testing for Huntington's disease: the experience of the UK Huntington's Prediction Consortium. Eur J Hum Genet 2016;24:1396-1402.

8 Borry P, Stultiens L, Nys H, Cassiman J-J, Dierickx K. Presymptomatic and predictive genetic testing in minors: a systematic review of guidelines and position papers. Clin Genet 2006;70:374-381.

9 Richards FH. Predictive genetic testing of adolescents for Huntington disease: A question of autonomy and harm. Am J Med Genet A 2008;146A:2443-2446.

10 Duncan RE, Gillam L, Savulescu J, Williamson R, Rogers JG, Delatycki MB. Reply to Richards: 'Predictive genetic testing of adolescents for Huntington disease: A question of autonomy and harm'. Am J Med Genet A 2008;146A:2447-2448.

11 Department of Health. Reference guide to consent for examination or treatment, second edition 2009. COI: London, 2009.

12 Steinberg L, Cauffman E. Maturity of judgment in adolescence: Psychosocial factors in adolescent decision making. Law Hum Behav 1996;20:249-272.

13 Patenaude AF, Dorval M, DiGianni LS, Schneider KA, Chittenden A, Garber JE. Sharing BRCA1/2 test results with first-degree relatives: Factors predicting who women tell. J Clin Oncol 2006;24:700-706.

14 Bradbury AR, Patrick-Miller L, Egleston BL, Olopade OI, Daly $\mathrm{MB}$, Moore $\mathrm{CW}$, et al. When parents disclose BRCA1/2 test results: Their communication and perceptions of offspring response. Cancer 2012;118:3417-3425.

15 Van Der Meer LB, Van Duijn E, Wolterbeek R, Tibben A. Adverse childhood experiences of persons at risk for Huntington's disease or BRCA1/2 hereditary breast/ovarian cancer. Clin Genet 2012;81:18-23.

16 Bradbury AR, Dignam JJ, Ibe CN, Auh SL, Hlubocky FJ, Cummings SA, et al. How often do BRCA mutation carriers tell their young children of the family's risk for cancer? A study of parental disclosure of BRCA mutations to minors and young adults. J Clin Oncol Off J Am Soc Clin Oncol 2007;25:3705-3711.

17 Godino L, Turchetti D, Jackson L, Hennessy C, Skirton H. Impact of presymptomatic genetic testing on young adults: a systematic review. Eur J Hum Genet 2016;24:496-503.

18 Corbin JM, Strauss AL. Basics of qualitative research : techniques and procedures for developing grounded theory. 2014.

19 Ferrari G, Rosina A, Sironi E. Beyond good intentions: the decision-making process of leaving the family of origin in Italy. Dondena Work Pap 2014;60:1-23.

20 Istat. Giovani.Stat. 2016. http://dati-giovani.istat.it/Index.aspx (accessed 10 December 2016).

21 Duncan RE, Gillam L, Savulescu J, Williamson R, Rogers JG, Delatyckil MB. 'Holding your breath': Interviews with young people who have undergone predictive genetic testing for Huntington disease. Am J Med Genet A 2007;143A:1984-1989.

22 Patenaude AF, Tung N, Ryan PD, Ellisen LW, Hewitt L, Schneider KA, et al. Young adult daughters of BRCA1/2 positive mothers: What do they know about hereditary cancer and how much do they worry? Psychooncology 2013;22:2024-2031.

23 Hoskins LM, Werner-Lin A, Greene MH. In their own words: treating very young BRCA1/2 mutation-positive women with care and caution. PLoS One 2014;9:e87696.

24 Metcalfe A, Coad J, Plumridge GM, Gill P, Farndon P. Family communication between children and their parents about inherited genetic conditions: a meta-synthesis of the research. Eur J Hum Genet 2008;16:1193-1200.

25 Metcalfe A, Plumridge G, Coad J, Shanks A, Gill P. Parents' and children's communication about genetic risk: a qualitative study, learning from families' experiences. Eur J Hum Genet 2011;19:640-646.

26 Hamilton R. Being young, female, and BRCA positive. Am J Nurs 2012;112:26.

27 Arnett JJ, Jensen J. Emerging adulthood: A theory of development from the late teens through the twenties. Am Psychol 2000;55:469-480.

28 Arnett JJ, Tanner JL. Emerging adults in America: Coming of age in the 21st century. Washington, DC: American Psychological Association; 2006.

29 Richards FH. Maturity of judgement in decision making for predictive testing for nontreatable adult-onset neurogenetic conditions: a case against predictive testing of minors. Clin Genet 2006;70:396-401.

30 Lindenmeyer A, Griffiths F, Hodson J. 'The family is part of the treatment really': a qualitative exploration of collective health narratives in families. Health (London) 2011;15:401-415.

31 Hoskins LM, Roy KM, Greene MH. Toward a new understanding of risk perception among young female BRCA1/2 'previvors'. Fam Syst Heal 2012;30:32-46.

32 Broadstock M, Michie S, Marteau T. Psychological consequences of predictive genetic testing: a systematic review. Eur J Hum Genet 2000;8:731-738.

33 Gong P, Fanos JH, Korty L, Siskind CE, Hanson-Kahn AK. Impact of huntington disease gene-positive status on presymptomatic young adults and recommendations for genetic counselors. J Genet Couns 2016. https://doi.org/10.1007/s10897016-9951-z.

34 Rew L, Mackert M, Bonevac D. A systematic review of literature about the genetic testing of adolescents. J Spec Pediatr Nurs 2009;14:284-294.

35 Werner-Lin A, Ratner R, Hoskins LM, Lieber C. A survey of genetic counselors about the needs of 18-25 year olds from families with hereditary breast and ovarian cancer syndrome. $\mathrm{J}$ Genet Couns 2015;24:78-87.

36 Gaff CL, Lynch E, Spencer L. Predictive testing of eighteen year olds: counseling challenges. J Genet Couns 2006;15:245-251. 